\title{
Governing by visual shapes: university rankings, digital education platforms and cosmologies of higher education
}

Mathias Decuypere (KU Leuven, Belgium) \& Paolo Landri (CNR-IRPPS, Italy)

mathias.decuypere@kuleuven.be

Keywords: University rankings, digital education platforms, Science and Technology Studies, UMultirank, critical methodology, data-visualization, cosmologies, higher education

\section{To cite this article:}

Decuypere, M., \& Landri, P. (2020). Governing by visual shapes: university rankings, digital education platforms and cosmologies of higher education. Critical Studies in Education. DOI:

$10.1080 / 17508487.2020 .1720760$

\section{Available at:}

https://doi.org/10.1080/17508487.2020.1720760

\begin{abstract}
University rankings have become commonplace in higher education. Traditional quantified rankings do not merely measure educational performance: they equally grant status, enforce competition between institutions, and are emblematic for the ongoing capitalization of higher education. Drawing on the field of Science and Technology Studies, this article undertakes an up-close, critical analysis of one ranking platform: U-Multirank. Explicitly recognizing the downsides of the football league mentality that is currently present in traditional league-table university rankings, U-Multirank provides a multidimensional and visual way of ranking higher education institutes that aims to take into account the diversity of the higher education sector and the complexity of what it is to evaluate educational performance. The article starts by analyzing U-Multirank as a situated place, that is, as embedded within a broader environment that is not exterior to the composition and eventual publication of the platform itself. After disentangling the platform's situatedness, the article traces the operations and actions performed by U-Multirank. Governing by visual shapes rather than merely by numbers, the platform acts as a kaleidoscopic optical device installing specific sorts of vision and specific forms of higher education. The article further elaborates how the platform configures specific, responsibilized and singularized, types of users, and concludes with some remarks regarding a more general shift towards more participatory forms of datafication and knowledge creation.
\end{abstract}

Paper submitted to the special issue 'Digital platforms and the changing forms of education' (Decuypere, Grimaldi \& Landri, eds.) 


\section{Introduction}

University rankings have taken up a central place in higher education policies for at least three decades, and have become increasingly popular since the mid-1990s (Hazelkorn, 2008). One of the earliest consistent approaches was the US News ranking, which started ranking higher US education institutions in 1983 (Shin \& Toutkoushian, 2011). Since then, a variety of research institutions and commercial media have started ranking universities and higher education (HE) institutions on a global scale. It is especially since 2003, when the Institute of Higher Education at Shanghai Jiao Tong University published the Academic Ranking of World Universities (ARWU), that university rankings have increasingly gained traction and public interest. The ARWU presented a list of the proclaimed 'top 500'-universities in the world. A year later, in 2004, the London magazine Times Higher Education Supplement published another list, the Times Higher Education World University Rankings (THE) of what were deemed to be the best 200 universities in the world (Brink, 2018). At present, there are more than 30 different global ranking systems of HE institutions, with the THE and ARWU remaining two of the most renowned.

Even though ranking systems vary greatly in what and how they measure, the vast majority relies almost exclusively on quantifiable measures of institutional performance (Shin \& Toutkoushian, 2011; Shore \& Wright, 2015). Based on such measures, these systems provide composite scores that are subsequently integrated into overall scores, which allows to rank HE institutes into singular 'league tables', listing universities from generally better to generally worse performing. Notwithstanding the fact that these league tables were initially met with an astounding amount of enthusiasm and rather unreflective attention, quite soon ranking systems were severely criticized (Brink, 2018). First of all, the specific ranking methods themselves, and the (often ideological) choices that are associated with the construction of these methods, are not without critiques. Rankings regularly operate from a strictly delineated idea of quality: by and large, indicators tend to be formulated from a highly specific idea about higher education, namely that of the comprehensive research-intensive university. Consequently, 'science-strong' and English-speaking universities are likewise gaining an implicit advantage (Marginson \& van der Wende, 2007). Additionally, it has not only been argued that the very act of ranking exaggerates sometimes minuscule differences between institutions but equally that adding up scores of individual measures is mostly not based on any sound methodological justification (Brink, 2018; Marginson, 2014). Closely related hereto, and second, is the often-raised critique that rankings theoretically oversimplify what HE is and entails. Since there (obviously) is no singular idea about what the ideal university is, rankings are by definition selective and arbitrary on which parameters to measure, thereby necessarily reducing what is deemed to be of importance in HE (Lingard, 2011; Lynch, 2015). Thirdly, ever since their proliferation, rankings seem to exert some sort of 'hypnotic power' (Marginson, 2014), which has led HE institutions, in an effort to attract the best international students and obtain a significant reputation, to fiercely compete with each other for a high rank. In that respect, rankings have not only intensified competition between universities, but equally between nation-states who aim to brand and network and, thereby, to forge elite identities which should establish a stronger competitive advantage (e.g. Lynch, 2015; Shin \& Toutkoushian, 2011).

Rankings, thus, materialize issues of power, as they favor certain agendas above others, impose hierarchical relations between universities or countries, and are used to confer prestige and status to a select amount of institutions (Pusser \& Marginson, 2013). Critical educational scholarship has continuously stressed not only that the very measurements of rankings tend to be biased towards measuring reputation and status (rather than actual performance), but equally that rankings enact a global HE market where students are explicitly addressed to search for, and study at, the 'best' HE institution possible (e.g. Collyer, 2013). More generally and fourthly, it is equally often argued that rankings are emblematic for the ongoing 
corporatization and capitalization of HE sector (Denzin \& Giardina, 2017; Lynch, 2015). Rankings and league tables are considered to be yet another manifestation of the 'capitalist-corporatist-marketing nexus in higher education'; a nexus with deleterious outcomes such as the downgrading of undergraduate education (Lincoln, 2012). From a critical perspective, rankings are furthermore closely associated with the rise and ongoing substantiation of a neoliberal audit culture, where virtually all aspects of social life are increasingly amenable to inspection and concomitant performance indicators (Amsler \& Bolsmann, 2012; Shore \& Wright, 2015). In education policy studies, these broader manifestations have been coined as a 'governing by numbers', in which education governance increasingly aims to reduce the complexities of education and educational performances into numerical indicators ('datafication') in order to manage and govern the educational sector more efficiently (e.g. Lingard, 2011).

The aim of this article, however, is not to give yet another critique of traditional university rankings and league tables, or of the rise and ongoing fetishization of neoliberalism in the HE sector (Decuypere \& Simons, 2019). Instead, the article zooms in on one particular initiative called U-Multirank. U-Multirank is a relatively new ranking that was originally seed-funded by the European Commission's Erasmus+ program, and that explicitly recognizes the downsides of the football league mentality presently reigning in the rankings sector. Drawing on the field of Science and Technology Studies, this article is more particularly approaching U-Multirank as an educational platform. That is to say, rather than considering UMultirank as a passive website that merely conveys or transmits neutral information, we consider UMultirank as an assemblage that draws a manifold of heterogeneous actors into a common space (i.e. that of the platform as interface). In doing so, the central interest of this article is to disentangle how this platform works, that is, how it is put to work and how it exerts itself a working force on its users (Sundström Sjöding, 2019).

\section{Digital education platforms: an STS approach}

In order to scrutinize U-Multirank as a digital education platform, we adopt a methodological approach informed by the field of Science and Technology Studies (STS). STS requires researchers to consider digital objects such as platforms not as the technological backdrop of social life, but rather to approach them as relational assemblages of social and material actors, which are both co-constitutive for the making and the fabrication of practices (Latour, 2005). As such, we do not approach STS as a stringent theoretical framework, but rather as a sensitizing device that allows disentangling how socio-technical assemblages such as platforms are 'done' and being relationally ordered, made and shaped (Decuypere, 2019a; Fuller, 2008).

In order to operationalize these general sensitivities, we draw on recent thinking about and research on the platformization of society in general (e.g. Gillespie, 2015; Srnicek, 2017; Van Dijck et al., 2018), and of the educational sector in particular (e.g. Decuypere, 2019b; Decuypere, 2019c; Williamson, 2016). More specifically, we approach platforms as devices that at once refer to a specific organizational form (the computational-architectural 'ground' upon which activities such as ranking might occur) and to the provision of a data infrastructure (allowing the presentation and mediation of visual and textual information, and the facilitation of communication, circulation, and interaction) (Lewis, 2017; Robertson, 2019; Srnicek, 2017). Platforms thus 'are simultaneously organizational forms that are highly technical, and technical forms that provide extraordinary organizational complexity to emerge' (Bratton, 2015, p. 41). Echoing the mutual co-production of materiality and sociality generally advocated by STS, platforms can be methodologically unpacked by focusing on three analytical levels. 
First of all, platforms need to be analyzed as situated places (ibid., p. 43). That is to say, platforms shouldn't be analyzed as separate technological silos, but rather as embedded within a social world that is not exterior to the platform itself (Gulson \& Sellar, 2019; Van Dijck et al., 2018). Analyzing platforms as situated places means not to merely be attentive to them in general terms, but rather and foremost being attentive to the specific mobilizations, categorizations, in broad, the specific processes and translations that make that platforms come into existence and thus operational at a certain point in time and space (e.g. Chang, 2019; Gorwa, 2019). Platforms, hence, become operable and are shaped by an intricate complex of actors that seek to give the platform a specific logic, working operation, or as we would like to term it here: a specific form (Decuypere, 2019a; van de Oudeweetering \& Decuypere, 2019; Ruppert, Law, \& Savage, 2013).

Next to investigating them as situated places, platforms can be scrutinized by investigating the specific plan of action that is inscribed in each and any platform (Bratton, 2015). Platforms are composed of interfaces, protocols, discursive elements, visualized data, and specific renderings of (educational) times and spaces, which are a conjoined production of social and material actors. Even though many platforms, as the resulting assemblage of all these actors, have the sheen of being formally neutral, they remain uniquely ideological in how they are structured and composed, and in how they thereby plan to convey specific messages and frame specific sorts of worlds (Gorwa, 2019; Srnicek, 2017). Platforms, thus, need to be researched at the level of the sorts of action they perform themselves since they substantiate a specific sort of world for the ones who make use of the platform: '[A platform] draws some things in and draws other things out, but foremost a platform is a drawing and framing machine' (Bratton, 2015, p. 46). As discursive, categorizing and aesthetic machines, platforms need to be investigated at the level of their diagrammatic and datafying operations, that is, at the level of which sorts of worlds they visually and textually portray (i.e. draw) through data practices, and which sorts of education they thereby stage, thus substantiating a particular sort of reality (Decuypere, 2019b, Decuypere, 2019c; Hartong, 2016; Jarke \& Breiter, 2019; Williamson, 2016; Woolgar \& Lezaun, 2013). In sum, platforms act: they perform specific operations (and others not); convey particular messages (and others not); draw some things in (and others out); make choices in what can appear (and what not), and how it is organized (or not).

Thirdly, in being situated places that seek to act through specific plans of action, platforms always generate user identities. This means that in setting the terms for participation and in drawing a particular - often highly personalized - world, platforms always equally draw or configure a particular type of user, which they subsequently seek to ensnare in their design (Bratton, 2015, p. 44; Van Dijck et al., 2018; Woolgar, 1990). Without having to be considered as stringent master plans, platforms do consolidate and confine what users can and cannot do, and thus hold im- and explicit expectations towards their visitors (Gorwa, 2019). This is close to what Agre (1994) coined as the grammar of action present in each and every technology: the various ways in which platforms aim to structure user activity, and what this on its turn implies for the kind of user the platform has in mind and seeks to configure. What is conclusively in need of analysis, then, is how such grammar of action leads to various sorts of user enactment: the active shaping (and ensnaring) of particular sorts of users who are expected to perform specific actions, are assumed to take up various roles and are thereby being staged in delineated ways (Decuypere, 2019b).

In what follows, we present the results of this threefold material-semiotic analysis (Law, 2009), which was effectuated by drawing on available online documentation about the platform as well as on the various texts, visualizations, scripts and interactive elements to be found on the platform itself. 


\section{A situated and contested place}

In considering U-Multirank as a situated place, we focus on how the platform is embedded within an intricate network of other actors, which allowed and enabled its eventual composition (Decuypere \& Simons, 2016; Webb \& Gulson, 2015). In order to get a better grasp of this network, we need to go back to 2006, when the European Commission (EC) issued a Communication that called for a modernization of European universities. In this Communication, the EC diagnosed that European universities were lagging behind in the global HE market and were in need of developing their potential more fully. However, it was immediately stressed that this did not mean that European universities, or the evaluation of their performing, should become standardized in any way: 'it is not necessary to follow an identical model in terms of the balance between education and research, have a similar approach to research or research training or offer similar academic services and subjects' (EC, 2007, n.p.). Acknowledging the shortcomings of existing rankings briefly afterwards, the intent was raised to not only have and value diversity in HE institutions, but equally to become a key player in the ranking sector itself: 'Becoming actors of rankings implies first of all that the definition of the "rules of play" is known and accepted in advance, and operationalized in a legitimate framework. (...) The reporter insists that this is neither about establishing hierarchy, nor is it about instituting a system "at various speeds", but rather about a recognition of that which is already a reality, viz. that all higher education institutions do not have the same objectives, and that it is thus inappropriate to judge them on uniform criteria' (Bourdin, 2008, pp. 73-74 - authors' translation). In the same document, Bourdin - a French Senator stressed that the then French Minister of Higher Education and Research, Valérie Pécresse, explicitly wanted to make use of the French Presidency of the EU to lay the foundations of a ranking based on common European criteria (p. 78).

Thus, in the beginning of the 2000s, different European actors mobilized the idea of establishing a European ranking system in which Europe would become a strategic key actor, rather than only being listed in other rankings such as ARWU and THE, which were criticized for being unidimensional by largely stressing the research capacities of universities. It is in that spirit that Odile Quintin, then European Commission Director-General for Education and Culture, issued a call for the development of a European ranking scheme, 'with emphasis on helping students make informed choices about where to study and encouraging their mobility' (Marshall, 2008). In other words, Bourdin, Pécresse, and Quintin all sought to make various actors interested in their idea, and subsequently issued this call in order to mobilize potential allies to make this idea material and operational (cf. Callon, 1984). According to the European Parliamentary Research Service think thank (EPRS, 2013), this call resulted in the EU funding two major feasibility programs: U-Map and U-Multirank.

U-Map, an initiative undertaken by the Dutch Center for Higher Education Policy Studies (CHEPS), started its first phase in 2005. The European funding received led to an extensive report that presented the initiative, which was directed at describing ('mapping') and classifying the diversity of European HE institutions (van Vught et al., 2010). The descriptions, or maps, were intended to portray the 'activity profiles' of these institutions, and this based on a variety of 14 different indicators inspired by the US Carnegie classification. However, after consultation with experts and stakeholders, the U-Map team concluded that 14 indicators ranged too broadly. Eventually, six dimensions were withheld: teaching and learning profile; student profile; research involvement; involvement in knowledge exchange; international orientation; and regional engagement. Importantly, these six dimensions were based on a qualitative agreement amongst stakeholders, and not on a statistically validated clustering of the original indicators (ibid.). Subsequently, various types of maps that could possibly present institutional activity on all these dimensions were constructed and deliberated: sunburst charts, circular charts, and so forth (see, for two examples, Figure 1(a-b)).

Decuypere, M., \& Landri, P. (2020). Governing by visual shapes: university rankings, digital education platforms and cosmologies of higher education. Critical Studies in Education. DOI: 10.1080/17508487.2020.1720760 

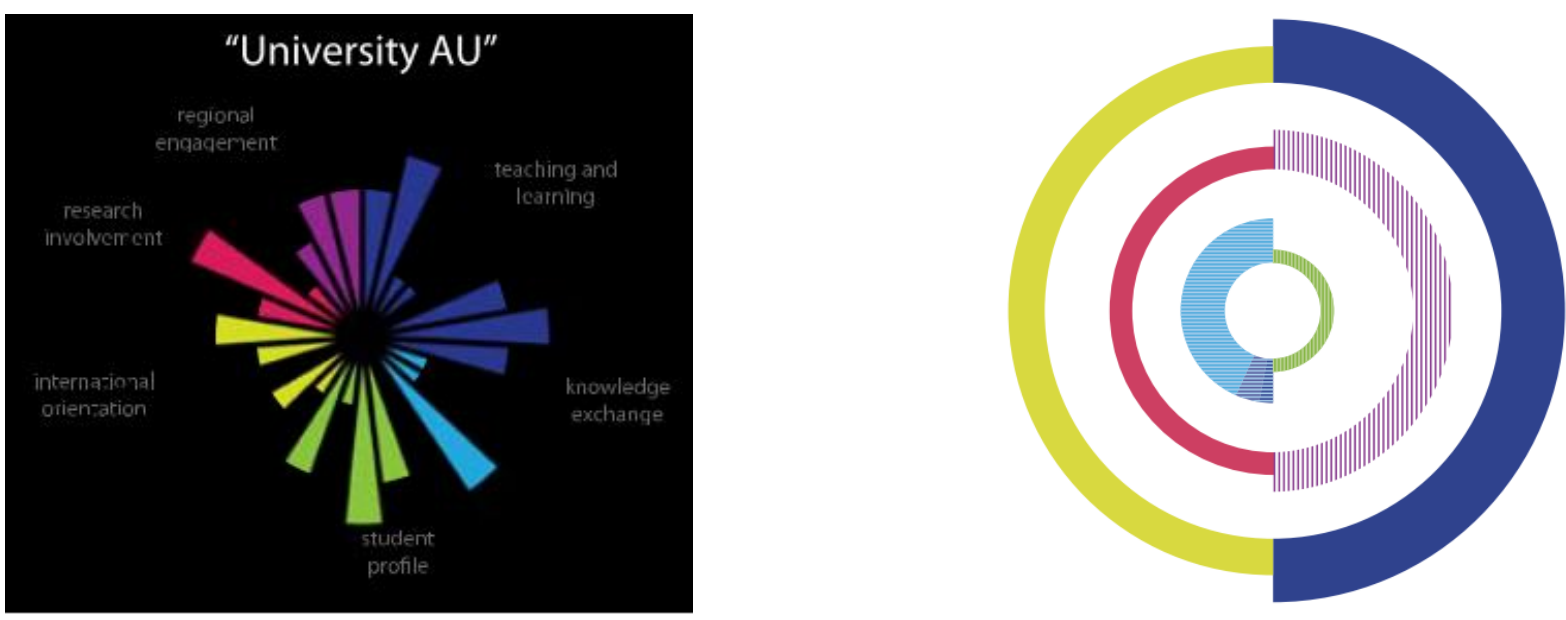

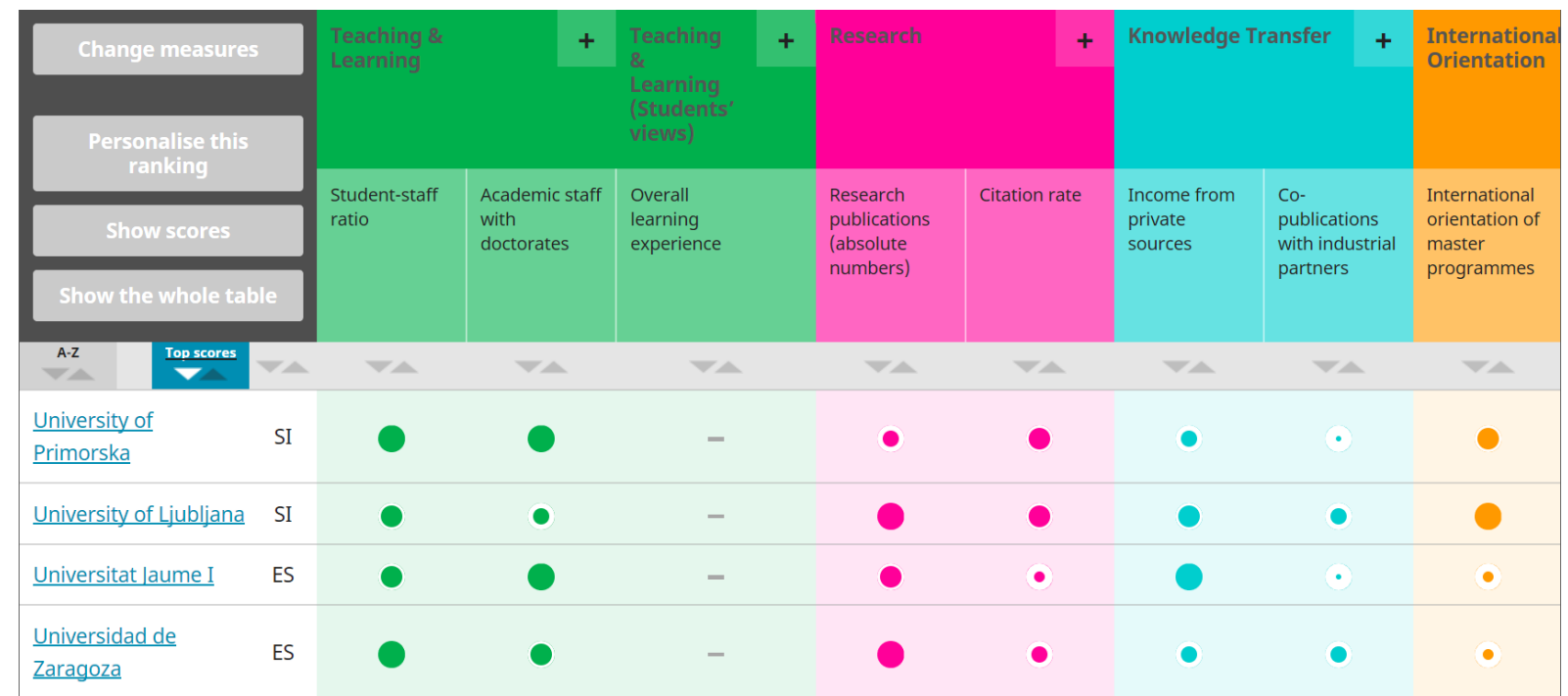
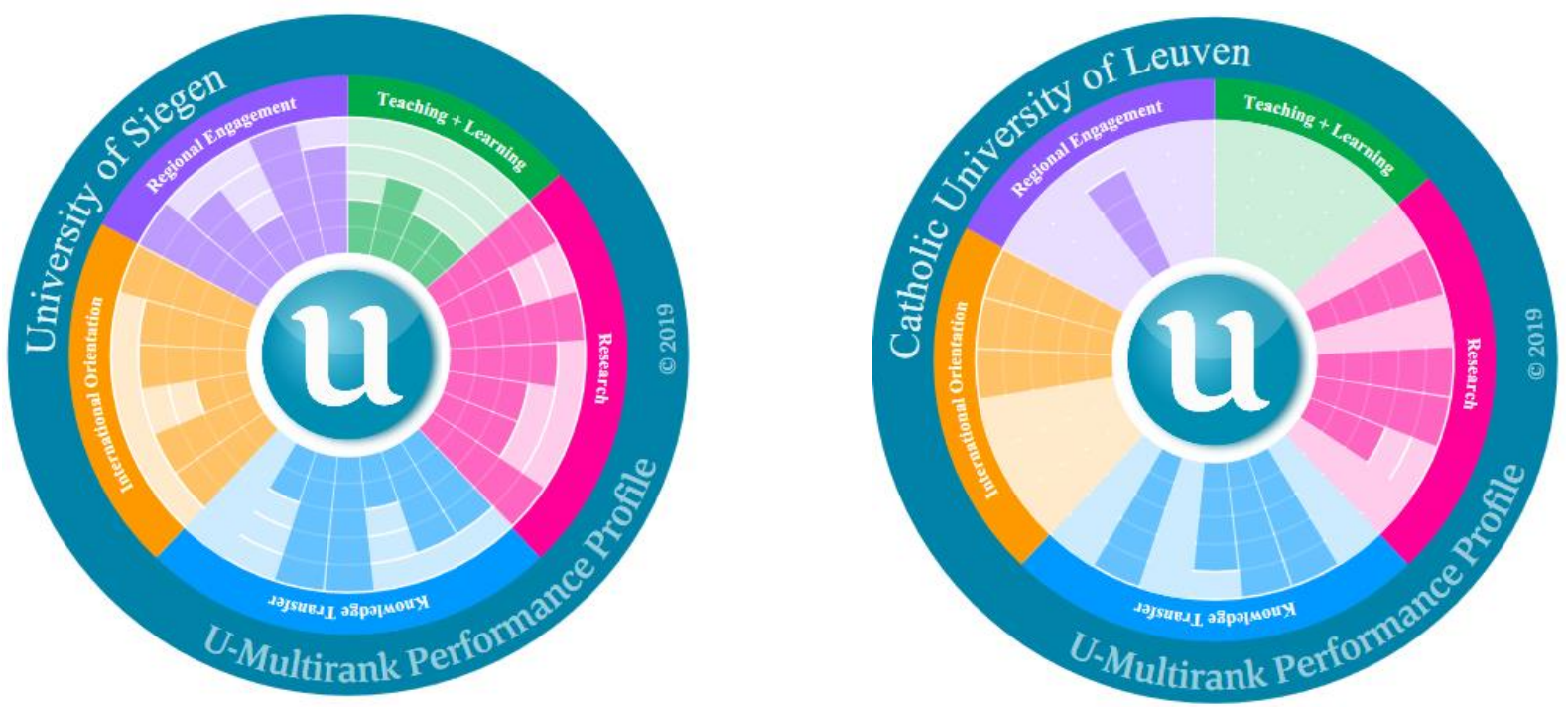

Figure 1. From top left to bottom right: (a) U-Map sunburst chart (van Vucht et al., 2010:39); (b) UMap circular chart (van Vucht et al., 2010:38); (c) Personal ranking (For source, see here); (d) Full performance profile of a university (For source, see here); (e) Incomplete performance profile of a university (For source, see here). 
In several European Communications, it is made very clear that U-Map is not to be confused with UMultirank, even though both initiatives are closely interwoven (CHEPS being one of the prime originators of U-Multirank, in conjunction with the German Center for Higher Education). U-Map's function, it was stated, was to act as a descriptive classification tool, whereas U-Multirank was explicitly directed at constructing university rankings. Put differently, U-Map was perceived as a university activity profiling tool, measuring what a university does, whereas U-Multirank was perceived as a university performance profiling tool, measuring how well a university does what it does (van Vught \& Ziegele, 2011). A threeyear feasibility study was needed in order to ascertain that such a multidimensional ranking with global aspirations could indeed be attained (van Vught \& Ziegele, 2011). Two years later, in 2013, U-Multirank was officially launched at an EU presidency conference in Ireland. At this launch Androulla Vassiliou, member of the EC, was particularly exasperated by other ranking systems: 'Our purpose is certainly not to provide yet another blunt instrument on which reputations fall or rise. U-Multirank is different. (...) U-Multirank is first and foremost there for you" (Vassiliou, 2013a). On another conference later that year, Vassiliou offered some insight into who is included in this 'you': 'U-Multirank is aimed at giving us a better picture of our higher education landscape. It will be a tool for all types of institutions, not just the top 500. (...) We want all stakeholders to be part of the process. U-Multirank is not an initiative which is done to the universities but with the universities' (Vassiliou, 2013b - underlining in original). In the middle of 2014, the platform went officially online and the first rankings were being published. Since then, it is proclaimed that the platform 'has changed the landscape' because of its multidimensional size and scope. This multidimensionality is portrayed as 'the fair way to compare universities globally' (U-Multirank, 2018, p. 6) since this allegedly allows the platform to present 'the true picture of quality and diversity' (ibid., p. 4).

In considering the platform's situatedness, what becomes increasingly lucid is how U-Multirank, from its very inception, aims to fabricate a very specific HE cosmology, which we use here as shorthand for the processes of trying to give the broad field of HE a particular form (cf. Packer, 2018; Decuypere, 2019a). It is clear that, in lagging behind other regions of the world in traditional ranking systems and in having the feeling that this is a misrepresentation of the 'true' quality of Europe's HE system, U-Multirank is intended to install different understandings about what HE is and how it should be evaluated. Put another way, the platform was made operable in such a way that it takes into account the variety of HE institutions, thereby seeking to better represent - and even protect - the diversity present in the HE sector. Universities, here, are being presented and shaped as multifarious yet vulnerable institutions that are in need of appropriate treatment, as both Bourdin and Vassiliou underscore. As such, U-Multirank itself comes into being as an undertaking that not only aims to present an at once more accurate and more just picture of HE institutions, it equally comes into being as a platform that seeks to care for the HE sector, which is allegedly being treated unrightfully by traditional ranking systems. It is not a coincidence that Figure 1(a-b) are so crammed: in search for an adequate presentation - a mode of ordering, as Annemarie Mol (2010) has it - that offers a maximum amount of diversity, the visualizations themselves seek to install a HE cosmology in which 'performance' is a layered, multifarious container concept rather than a singular composite score.

However, presenting the 'true picture' of quality comes with a price: working with such a variety of performance indicators necessitates the gathering of tremendous amounts of information. Whereas UMultirank at present partly gathers data from already existing data sources (i.c. bibliometric and patent data), in order to completely compose its rankings, the platform is crucially dependent on HE institutions (and student opinions) themselves to provide the necessary information. In order to be able to compose such a complex mode of ordering, the platform is thus depending on a myriad of data actors that are all in need of convincing in order to participate in the very construction of the platform's database (Callon, 
1984). From its inception, the EC was very aware of the fact that in order to construct such a complex, multidimensional picture of HE quality, it would especially need to interest HE institutions themselves and enroll them in the U-Multirank assemblage: 'As the Multirank (sic.) concept relies on the new data and the voluntary participation of institutions, gaining the buy-in of institutions will be crucial' (European Commission, 2011 - emphasis added). In that sense, it can be stated that the platform was conceived to co-produce itself together with its eventual users: without universities and students as data providers, there can be no complex picture of quality, which would ultimately end up in a platform that cannot be used by those very students and universities. Appealing to the diligence and voluntarism of universities, both the EC and U-Multirank again sought to enact highly specific forms of universities, i.e. universities as voluntary and conscious data providers (cf. Hartong, 2016). In short: universities that want a complex picture are implied to owe it to the platform that they co-construct the databases that the platform subsequently draws on - after all, this is 'the fair way to compare' (U-Multirank, 2018, p. 6).

Yet, these processes of performing a new HE cosmology were not received uniformly. In 2012, after the U-Multirank announcement of the EC, an article (not-coincidentally) written by the person in charge of the THE rankings feared that 'U-Multirank may be a waste of taxpayers' money' (Baty, 2012). In the same article, the UK Minister for Universities and Science argued that the platform could be viewed as an attempt by the EC to construct a set of rankings in which European universities 'do better than they appear to do in the conventional rankings' (ibid.). Interestingly, equally within academic circles, the platform was not very well received (see Brink, 2018 for an extensive overview). For instance, in the same period, universities belonging to the League of European Research Universities (LERU) started to boycott the platform because it was again conceived to be a waste of money, and potentially even a threat to the HE sector (Grove, 2013). This is especially remarkable given the fact that many LERU universities actively participated in the pilot phase of the platform and were members of the Network that was responsible for the aforementioned feasibility study. More recently, in 2016 the Coimbra Group - another elitist network of European universities - stated that even though U-Multirank is 'conceptually superior' to other rankings, the Group was generally disappointed in the platform: it was perceived to be characterized by some severe weaknesses in measuring the quality of HE, leading to half of the Group abstaining from active participation in the ranking (Coimbra, 2016 - cf. Marginson, 2014). Thus, it is clear that within academic circles there was, and still is, a considerable recalcitrance against the platform, and hence, that the multidimensional form of HE that U-Multirank aims to create is not self-evident (let alone unanimously approved of - cf. Woolgar \& Lezaun, 2013).

In sum, by zooming in on the platform as a situated place, what becomes clear is that U-Multirank is as much made operable by a specific assemblage of visions and convictions with respect to what HE is as it seeks to shape such a baseline vision itself. The platform, thus, is to be conceived as a produced achievement, which seeks to obtain value precisely through being different from other initiatives in the field. At the same time, the platform is equally to be conceived as a productive achievement, aiming to shape different cosmologies of HE.

\section{Quality as a shape: the ranking platform as kaleidoscope}

In order to disentangle the plan of action that is substantiated on U-Multirank, we focus on the various ways in which it allows (and steers) the user to rank universities in different sorts of ways, but equally already before that - the various ways in which it allows (and steers) the user to search for different universities. In that regard, the platform explicitly states that it is not clear-cut what a university is. 
Instead, what a university is, is partly depending on what the user of the platform needs or is in search of: as the platform's FAQ section explicitly states, users 'define the kind of universities they are interested in' (UMultirank, 2018, p. 5). The form of a university is, thus, partly depending on what the user intends this form to be. Nevertheless, this form is heavily entrenched in the platform qua situated place. As discussed above, U-Multirank originated in close connection with the U-Map initiative, and up till today the five major categories that are used to classify and divide universities into (teaching + learning; research; knowledge transfer; international orientation; regional engagement) are clearly based on the six dimensions mentioned previously. As a ranking engine, U-Multirank's historical situatedness in a larger European policy space thus largely contributes to what users can search for today.

Based on a database consisting of bibliometric and patent data on the one hand, and university and student provided data on the other hand, U-Multirank allows the user to rank in three distinct manners. The first way entails the creation of personalized rankings. One of the proclaimed hallmarks of the platform is that it at once allows users to compare similar institutions ('like-with-like') and that it allows doing so in such a way that it addresses their own personal exigencies and needs. This not only ensnares these users in a highly delineated manner (see below), it equally shows that the platform operates as a personalization tool that is centrally directed at creating tailored rankings in which users are put to work themselves. In order to produce such personalized rankings, users need to provide a couple of parameters that they deem to be personally important, by ticking some preferences. These preferences are the designated area of study, such as education or chemistry ('what subject are you interested in'), and some criteria you want to search for, such as the expenditure on research or universities' income of private sources ('what do you want to compare'; based on the five dimensions elucidated above). In doing so, the platform draws a range of subjects of interest together, and the platform explicitly conveys the message that it will become more comprehensive 'over the next few years', as such framing the engine as an incomplete project that is on a quest of becoming ever more accurate (cf. Srnicek, 2017).

Figure 1(c) displays how a personalized ranking looks like. Co-producing visualizations together with the user, this ranking compares institutions on the subject 'computer science', and with as personally selected criteria medium expenditure on teaching and research. HE performance, or 'quality', is taking the shape of an amalgamation of spheres here, where universities are made isomorph in view of the specific ranking produced in conjunction with the user. That is to say, HE institutions are being molded into the same shape in view of what one is comparing (cf. Hartong, 2016). It is clear that Figure 1(c) requires users to become literate in interpreting such visualizations: even though the University of Primorska is ranked before that of Ljubljana, it is not at all self-evident how to interpret this multidimensional differing in performance, let alone what this would concretely imply: how such visualizations are produced (and on which measures they are based) is consultable on a dedicated webpage, but in and on themselves they give the impression of being at once 'uncooked' and mirroring the 'true' (as in veracious) performance of HE institutions (Decuypere, 2019b; Williamson, 2016). Enacting a persuasive regime of visibility, quality as a composite yet isomorphic shape - is being created in a mutable and ever mobile space of commensuration that transmogrifies according to the personal requirements of each and every user.

The second way is a ranking of distinct institutional performance profiles. In contrast to personalized rankings, these types of rankings are 'readymade' and directly at hand for the user who is interested in the performance of one specific university (or who wants to compare a limited amount of dedicated universities with each other). Here again, we see the crucial importance of situating the epistemic authority (and its associated performative operability) that is inscribed in different types of visualizations (Decuypere, 2016; Decuypere \& Simons, 2016). Visualized in a more polished manner than Figures 1a$\mathrm{lb}$, Figure 1d showcases the full performance profile of a university, that is, of a university of which all Decuypere, M., \& Landri, P. (2020). Governing by visual shapes: university rankings, digital education platforms and cosmologies of higher education. Critical Studies in Education. DOI: 10.1080/17508487.2020.1720760 
information was obtained. Visually ordering universities on the aforementioned five dimensions, these sunburst charts display quality as a multidimensional presentation of how a singular university performs. Compared to U-Map's sunburst charts, the complex mode of ordering is largely similar, even though the double meaning of ' $U$ ' is being rendered way more visible in these new sunburst charts (' $U$ ' as shorthand for University vs. ' $U$ ' as you, stressing that it is the user who ranks, thereby 'cinematizing data excitement' - Souto-Otero \& Beneito-Montagut, 2016). Within each dimension, various rays of performance are being juxtaposed, shedding light on differential facets of performing (or obscuring them, in the case of non-presence). Thus, in order to give HE institutions a visually ordered (sunburst) shape, these institutions need to be performed as heterogeneously as possible, yet in a manner which is at once heavily standardized and deeply entrenched in the platform's generic fivefold of dimensions (cf. Carvalho, 2014).

Importantly, and as discussed above, visualizing institutional performance is depending on the cooperation of these institutions themselves. As we have seen, there is a substantial amount of resistance against UMultirank, with many institutions refusing any cooperation. However, the platform visualizes such unruly behavior very clearly, by explicitly showing gaps in institutional performance (Figure 1(e)). Presenting non-available data as if they refer to the non-performing of institutions on these specific aspects, UMultirank visually inscribes the recalcitrance of these institutions and visually sanctions them for their noncomplying. This makes it particularly clear that the visual ordering performed by the platform is not an innocuous process of representation, but a heavily politicized achievement that is, on its turn, always a politicizing undertaking (Lawn, 2013).

A third major way in which U-Multirank allows users to rank is by national performance. In instructive infographics, the platform conveniently displays some crucial facts about the performing of a specific country, such as average tuition costs and different dimensions on which national universities tend to perform well. Interestingly, accompanying country reports equally present HE institutions that overall have the highest number of top scores in national ... league tables, where the university with the largest composite score is ranked highest (e.g. U-Multirank, 2019). Even though there is a lot to say about this displaying of singularly ranked institutions, of importance here is not only that this league table is yet another manifestation of how universities are being per-formed (that is, being given yet another specific form next to that of tables, rays, etc.), but equally that of all of these forms, this is the only one that is not seeking to display quality as a multidimensional, visual shape (Brink, 2018). As such, this singular numerical portrayal seems to be strangely out of touch with the other cosmologies of HE that are being fabricated through actively ranking on the platform (and that were advocated for when constructing the platform, see above).

In sum, U-Multirank acts as a drawing machine that installs a visual culture that redefines both what it is to see and what there is to see (Latour, 1986). As a search engine that presents multifarious forms of universities, the platform operates as an optical device that substantiates a type of flat vision that is maximally attractive and synoptic; amenable to visual inspection in the blink of an eye. It acts as a kaleidoscope where attractive synoptic shapes, made up out of an intricate complex of massive amounts of data, are to be viewed as the end stage of a sophisticated 'cascade of inscriptions' (ibid.) that only works to the extent that it succeeds in operating as a rhetoric device. These ready-to-hand visualizations and tabulations, as different modes of representation, act as emblem of the platform's authority in diagnosing and illuminating, and thereby seeing, the true complexity of HE performing (cf. Lynch, 1991). It is important to remark here that this governing by shapes does not act as a substitution of more traditional forms of governance that seek to govern by numbers. Rather, governing by shapes necessitates the further encapsulation of cascades of numbers over and beyond the already existing processes of datafication at work in order to turn reality into such numbers. Rather than supplanting numbers, ranking by and through Decuypere, M., \& Landri, P. (2020). Governing by visual shapes: university rankings, digital education platforms and cosmologies of higher education. Critical Studies in Education. DOI: 10.1080/17508487.2020.1720760 
shapes allows platforms to at once display cascades of inscriptions in a pleasant, aesthetic manner and further complicate the numerical-ordinal basis of traditional rankings systems (cf. Fourcade, 2016). It is precisely on this tension between simplicity and attractivity on the one hand, and complexity and multidimensionality on the other hand, that U-Multirank is constantly balancing: the platform constantly oscillates between operating as a center of aggregation (of performances into figures and tables) and as a center of particularization (of unique institutions that should not be standardized).

\section{Ensnaring through singularizing and responsibilizing}

In the previous section, our analysis showed how U-Multirank acts and the various kaleidoscopic operations it performs in and through ranking. In this section, we briefly account for two ways in which the platform seeks to ensnare its visitors as specific sorts of users.

U-Multirank users are, first and foremost, staged as singular individuals that need to undertake action themselves, in order to be able to see HE performance. As shown above, the platform operates through shapes that visitors need to co-construct, by feeding the platform the necessary desired input in order to visualize what is of importance for the individual user (Brink, 2018). Yet, requiring that visitors of the platform are active is not a neutral operation, since this requires users to get out of the 'read-only' mode of data systems, in which information is presented in a way that cannot be altered (Schleicher, 2019, np), or to put this differently: it requires users to handle these data systems as plastic and configurable givens. Per Williamson (2016, p. 133), this plasticity by means of which different performances can be visualized incites and ensnares users as 'participatory actors in the flow of comparative data'. U-Multirank only works to the extent that singularized 'prosumers' work for the platform itself. Users, thus, are ensnared as active cooperators and contributors to the platform - a move that is highly reminiscent of how many traditional platforms such as YouTube and Facebook operate (Van Dijck et al., 2018). Whereas the platform takes up the role of curator of data and data presentation, users - drawn out of the read-only mode - are at once ensnared as data providers and as producers of personalized shapes. Thus, U-Multirank's grammar of action requires interactivity of each individual user in order for the platform to be able to operate. This immediately implies, first, that users can bypass a detailed apprehension of numbers in favor of visual representations should they wish so, and second, that these users are thus to be enacted as singular individuals who are in need of what relatively matters to their person, rather than as diligent adopters of, and unconditional believers in, the absoluteness of composite scores that are assumed to speak for themselves (Decuypere et al., 2011; Shore \& Wright, 2015).

However, despite providing personalized rankings as unique selling point - and partly constructed through the platform-visitor-as-prosumer - what ultimately enables such personalization is an entrenched standardization of categories on which users can compare and of the categories that are deemed worthy of measurement. As such, ensnared as singular prosumers, both universities and U-Multirank visitors are nevertheless greatly embedded in the standardized confines of the platform, which are ultimately nonnegotiable. Ensnaring users likewise, the platform enacts and actively shapes a space of equivalence that operates on a manifold of pre-formatted and standardized parameters and scales. In this myriad of standardized options, the user is called to be responsible, i.e. not to cherry-pick between institutions but rather to decide what is of value for oneself (and what is not) and what matters for oneself (and what does not), and all this before one starts the actual operation of creating individually-tailored rankings (ibid.). The consequence of such responsibilizing forms of ensnaring, of course, is that 'there is no reference 
anymore to something outside [users] themselves and beyond their control' (Simons, 2014, p. 722), and consequently, that making right choices becomes the sole responsibility of users themselves.

\section{Concluding thoughts}

This article offered an analysis of a university ranking platform that seeks to move beyond the crude mechanisms at work when ranking HE institutions per composite score in league tables (cf. Shin \& Toutkoushian, 2011). In producing new types of vision, which subsequently inevitably configure the ones who look through this optical device, U-Multirank is promoting much more than just a reforming of the ranking sector; it is also creating new forms of authority and control, specific ways of governing, and enacting new types of users (cf. Lawn, 2013; Sauder \& Espeland, 2009; Souto-Otero \& Beneito-Montagut, 2016). As a nuanced way to adhere to the specificities, particularities, and situatedness of digital education platforms, this article then demonstrated the general methodological importance of extensive critical analyses that stay close to the level of practice whilst at the same time taking into account variable understandings of these platforms and that, in doing so, display the variegated effects that digital education platforms yield (Bratton, 2015; Gillespie, 2015).

But what about U-Multirank as a specific instantiation of the HE ranking sector? We conclude by arguing that U-Multirank, emblematic for broader shifts towards the platformization of the education sector, marks a crucial shift towards more participatory forms of datafication and knowledge creation. Up till recently, the ranking sector as a whole has been characterized by a strict separation between HE institutions and users on the one hand, and ranking systems on the other hand. With Marres (2017, p. 167), we could denote such a model as a model of digital paternalism, in which ranking agencies are configuring the HE sector at once as a resource and as an audience of ranking results. Yet as a platform, and whilst still appealing to the desire of institutions to increase operability and optimization (cf. Thompson \& Sellar, 2018), U-Multirank explicitly aims to go beyond such paternalism. Instead, the platform allows both HE institutions and its visitors to participate in the creation of data (c.q. visualized shapes). In that respect, the platform is not alone: in general, platformization appears to lead to different ranking systems (e.g. THU) being tilted towards some sort of interactive participation (and, it might be surmised, towards an increasingly interactive governing by visual shapes).

However, and as argued, whilst this changes the distribution of who does what, and perhaps equally of ownership of processes of datafication, it does not redistribute epistemic authority or agency. On the platform - and again we think this is emblematic for the platformization of education as a whole participation can thus be denoted as a limited, logistical form of participation, which allows users to coenquire the various dimensions on which HE institutions are good at. Yet, this does not redistribute epistemic capacities, and thus essentially leaves the authority in the creation of HE cosmologies strictly in the hands of the platform designers and coders themselves (Marres, 2017). Consequently, users (and HE institutions) are not given the opportunity to ask fundamental normative questions about what HE is good for - a fact that partially accounts for the described recalcitrance of many HE institutions (Brink, 2018; Van Dijck et al., 2018). Such questions are inherently linked to the public character of (higher) education and would necessarily imply that users and HE institutions would be implicated in (participating in) the construction of the various HE cosmologies enacted on (and through) educational platforms. If this argument holds true, all this would imply that digital education platforms are perhaps in need of more experimental forms of participation, in which it is not only the prerogative of scholars to ask - in the safe confines of academic articles - questions about which forms of higher education we want and which are 
to be desired, about which dimensions these forms should have, about what quality is and should be, and ultimately, about the desirability of ranking platforms themselves.

\section{References}

Agre, P. E. (1994). Surveillance and capture. Two models of privacy. Information Society, 10(2), 101-127.

Amsler, S. S., \& Bolsmann, C. (2012). University ranking as social exclusion. British Journal of Sociology of Education, 33(2), 283-301.

Baty, P. (2012). U-multirank may be a waste of taxpayers' money. Retrieved from https://www.timeshighereducation.com/world-university-rankings/news/u-multirank-may-be-awaste-of-taxpayers-money

Bourdin, M. J. (2008). Rapport d'information fait au nom de le délégation du Sénat pour la Planification sur le défi des classements dans l'enseignement supérieur. Paris: Sénat Session extraordinaire de 2007-2008.

Bratton, B. (2015). The stack: On software and sovereignty. Cambridge, MA: MIT Press.

Brink, C. (2018). The soul of a university. Why excellence is not enough. Bristol: Bristol University Press.

Callon, M. (1984). Some elements of a sociology of translation: domestication of the scallops and the fishermen of st brieuc bay. The Sociological Review, 32(1_suppl), 196-233.

Carvalho, L. M. 2014. The Attraction of Mutual Surveillance of Performances: PISA as a Knowledgepolicy Instrument. In T. Fenwick, E. Mangez, and J. Ozga (Eds.), Governing Knowledge: Comparison, Knowledge-based Technologies and Expertise in the Regulation of Education (pp. 58-72). London: Routledge.

Chang, E. (2019). Beyond workforce preparation: Contested visions of 'twenty-first century' education reform. Discourse, 40(1), 29-45.

Coimbra Group (2016). U-Multirank today: position paper of the coimbra group. Retrieved from http:/ / www.coimbra-group.eu/wp-content/uploads/U-Multirank-today-Position-Paper-1.pdf

Collyer, F. (2013). The production of scholarly knowledge in the global market arena: University ranking systems, prestige and power. Critical Studies in Education, 54(3), 245-259.

Commission, E. (2007). Modernising universities. Retrieved from https://eur-lex-europaeu.kuleuven.ezproxy.kuleuven.be/legal-content/EN/TXT/?uri=LEGISSUM:c11089

Decuypere, M. (2016). Diagrams of Europeanization: European Education Governance in the Digital Age. Journal of Education Policy, 31(6), 851-872. doi:10.1080/02680939.2016.1212099

Decuypere, M. (2019a). STS in/as education: where do we stand and what is there still to gain? Some outlines for a future research agenda. Discourse: Studies in The Cultural Politics of Education, 40(1), 136-145. doi:10.1080/01596306.2018.1549709

Decuypere, M. (2019b). Open Education platforms: Theoretical ideas, digital operations and the figure of the open learner. European Educational Research Journal, 18(4),439-460. doi:10.1177/1474904118814141. 
Decuypere, M. (2019c). Researching educational apps: ecologies, technologies, subjectivities and learning regimes. Learning, Media and Technolgy, 44(4), 414-429. doi:10.1080/17439884.2019.1667824

Decuypere, M, \& Simons, M. (2016). Relational thinking in education: topology, sociomaterial studies and figures. Pedagogy, Culture \& Society, 24(3), 371-386. doi:10.1080/14681366.2016.1166150

Decuypere, M, \& Simons, M. (2019). Continuing attachments in academic work in neoliberal times: On the academic mode of existence. Critical Studies in Education, 60(2), 226-244. doi:10.1080/17508487.2016.1240095

Decuypere, M, Simons, M, \& Masschelein, J. (2011). "perform, measure accurately, optimise”: on the constitution of (evidence-based) education policy. International Studies in Sociology of Education, 21(2), 115135. doi: $10.1080 / 09620214.2011 .575101$

Denzin, N. K., \& Giardina, M. D. (2017). Qualitative inquiry in neoliberal times. In N. K. Denzin \& M. D. Giardina (Eds.), Qualitative inquiry in neoliberal times, 1-16. New York: Routledge.

EPRS. (2013). University ranking and U-multirank. Retrieved from https: / / epthinktank.eu/2013/10/08/university-ranking-and-u-multirank/

European Commission. (2011). Supporting growth and jobs - An agenda for the modernisation of Europe's higher education systems. Luxemburg: COM (2011) 567 final.

Fourcade, M. (2016). Ordinalization: Lewis A. Coser Memorial Award for Theoretical Agenda Setting 2014. Sociological Theory, 34(3), 175-195.

Fuller, M. (2008). Software Studies: A Lexicon. Cambridge, MA: The MIT Press.

Gillespie, T. (2015, April-June). Platforms intervene. Social Media and Society, 1-2.

Gorwa, R. (2019). What is platform governance? Information Communication and Society, 22(6), 854-871.

Grove, J. (2013). Leru pulls out of eu's u-multirank scheme. Retrieved from https://www.timeshighereducation.com/news/leru-pulls-out-of-eus-u-multirankscheme/2001361.article

Gulson, K. N., \& Sellar, S. (2019). Emerging data infrastructures and the new topologies of education policy. Environment and Planning D: Society and Space, 37(2), 350-366.

Hartong, S. (2016). Between assessments, digital technologies and big data: The growing influence of 'hidden' data mediators in education. European Educational Research Journal, 15(5), 523-536.

Hazelkorn, E. (2008). Learning to live with league tables and ranking: The experience of institutional leaders. Higher Education Policy, 21(2), 193-215.

Jarke, J., \& Breiter, A. (2019). Editorial: The datafication of education. Learning, Media and Technology, 44(1), 1-6.

Latour, B. (1986). Visualisation and cognition: Drawing things together. Knowledge and Society: Studies in the Sociology of Culture past and Present, 6, 1-40.

Latour, B. (2005). Reassembling the social: An introduction to actor-network-theory. Oxford: Oxford University Press. 
Law, J. (2009). Actor network theory and material semiotics. In B. S. Turner (Ed.), The new Blackwell companion to social theory (pp. 141-158, 3rd ed.). Oxford: Wiley-Blackwell.

Lawn, M. (2013). The rise of data in education systems: Collection, visualization and use. London: Symposium Books.

Lewis, S. (2017). Governing schooling through 'what works': the oecd's pisa for schools. Journal of Education Policy, 32(3), 281-302.

Lincoln, Y. S. (2012). The political economy of publication: Marketing, commodification, and qualitative scholarly work. Qualitative Health Research, 22(11), 1451-1459.

Lingard, B. (2011). Policy as numbers: Ac/counting for educational research. Australian Educational Researcher, 38, 355-382.

Lynch, K. (2015). Control by numbers: New managerialism and ranking in higher education. Critical Studies in Education, 56(2), 190-207.

Lynch, M. (1991). Pictures of nothing? Visual Construals in Social Theory, 9(1), 1-21.

Marginson, S. (2014). University rankings and social science. European Journal of Education, 49(1), 45-59.

Marginson, S., \& van der Wende, M. (2007). To rank or to be ranked: The impact of global rankings in higher education. Journal of Studies in International Education, 11(3/4), 306-329.

Marres, N. (2017). Digital sociology. Cambridge, UK: Polity.

Marshall, J. (2008). New ranking scheme for universities. Retrieved from https: / / www. universityworldnews.com/post.php?story $=2008112015513946 \&$ query $=$ university + rank ing

Mol, A. (2010). Actor-network theory: Sensitive terms and enduring tensions. Kölner Zeitschrift Für Soziologie Und Sozialpsychologie, 50(1), 253-269.

Packer, M. J. (2018). The science of qualitative research. Cambridge University Press.

Pusser, B., \& Marginson, S. (2013). University rankings in critical perspective. The Journal of Higher Education, 84(4), 544-568.

Robertson, S. L. (2019). Comparing platforms and the new value economy in the academy. In R. Gorur, S. Sellar and G. Steiner-Khamsi (Eds.), Comparative methodology in the era of big data and global neworks (pp. 169-186). London: Routledge.

Ruppert, E., Law, J., \& Savage, M. (2013). Reassembling social science methods: The challenge of digital devices. Theory, Culture \& Society, 30(4), 22-46.

Sauder, M., \& Espeland, W. N. (2009). The discipline of rankings: Tight coupling and organizational change. American Sociological Review, 74, 63-82.

Shin, J. C., \& Toutkoushian, R. K. (2011). The past, present, and future of university rankings. In J. C. Shin, R. K. Toutkoushian, U. Teichler (Eds.), University rankings (pp. 1-16). Cham: Springer.

Shore, C., \& Wright, S. (2015). Governing by numbers: Audit culture, rankings and the new world order. Social Anthropology, 23(1), 22-28. 
Simons, M. (2014). Governing education without reform: The power of the example. Discourse: Studies in the Cultural Politics of Education, 36(5), 712-731.

Souto-Otero, M., \& Beneito-Montagut, R. (2016). From governing through data to governmentality through data: Artefacts, strategies and the digital turn. European Educational Research Journal, 15(1), 14 33. [Crossref],

Srnicek, N. (2017). Platform capitalism. Cambridge, UK: Polity.

Sundström Sjöding, E. (2019). Where is the critical in literacy? Örebro University (Unpublished dissertation).

Thompson, G., \& Sellar, S. (2018). Datafication. Testing Events and The outside Of Thought. Learning, Media and Technology, 43(2), 139-151.

U-Multirank. (2018). Frequently asked questions (FAQ). Retrieved from https://www.umultirank.org/export/sites/default/press-media/documents/FAQ U-

Multirank 2018.pdf

U-Multirank. (2019). U-Multirank 2019: Belgian universities in global comparison. Retrieved from https://www.umultirank.org/export/sites/default/press-media/documents/UMR-

Proposal/Country-Reports-2019/BE-Country-report-2019.pdf

van de Oudeweetering, K., \& Decuypere, M. (2019). Understanding openness through (in)visible platform boundaries: a topological study on MOOCs as multiplexes of spaces and times. International Journal of Educational Technology in Higher Education, 16, Art.no. 28. doi:10.1186/s41239-019-0154-1

Van Dijck, J., Thomas P., \& Martijn De Waal et al. (2018). The platform society: Public values in a connective world. Oxford: Oxford University Press.

van Vught, F. A., Kaiser, F., File, J. M., Gaethgens, C., Peter, R., Westerheijden, D. F. (2010). The European classification of higher education institutions. The Netherlands: Enschede.

van Vught, F. A., \& Ziegele, F. (2011). Design and testing the feasibility of a multidimensional global university ranking. Retrieved from https://www.eurashe.eu/library/quality-he/UMultirank Design\%20and\%20Testing\%20the\%20Feasibility\%20of\%20a\%20Multidimensional\%20Glo bal\%20University\%20Ranking.pdf

Vassiliou, A. (2013a). Launch of new university ranking. Retrieved from http://europa.eu.kuleuven.ezproxy.kuleuven.be/rapid/press-release SPEECH-13-77 en.htm

Vassiliou, A. (2013b). Opening up higher education to the world and the new university ranking, U-Multirank. Retrieved from http://europa.eu.kuleuven.ezproxy.kuleuven.be/rapid/press-release SPEECH-13306 en.htm

Webb, P. T., \& Gulson, K. N. (2015). Policy scientificity 3.0: Theory and policy analysis in-and-for this world and other-worlds. Critical Studies in Education, 56(1), 161-174.

Williamson, B. (2016). Digital education governance: Data visualization, predictive analytics, and 'realtime' policy instruments. Journal of Education Policy, 31(2), 123-141.

Woolgar, S. (1990). Configuring the user: the case of usability trials. The Sociological Review, 38(1), $58-$ 99. 
Woolgar, S., \& Lezaun, J. (2013). The wrong bin bag: A turn to ontology in science and technology studies? Social Studies of Science, 43(3), 321-340. 